Article

\title{
The Organization and Regulation of Full Contact Martial Arts: A Case Study of Flanders
}

\section{Jikkemien Vertonghen *, Marc Theeboom, Els Dom, Veerle De Bosscher and Reinhard Haudenhuyse}

Department of Sports Policy and Management, Vrije Universiteit Brussel, Pleinlaan 2, 1050 Brussels, Belgium; E-Mails: marc.theeboom@vub.ac.be (M.T.); els.dom@vub.ac.be (E.D.); vdebossc@vub.ac.be (V.D.B.); Reinhard.Haudenhuyse@vub.ac.be (R.H.)

* Author to whom correspondence should be addressed; E-Mail: jikkemien.vertonghen@vub.ac.be; Tel.: +32-(0)2-629-27-71; Fax: +32-(0)2-629-28-99.

External Editors: Bryan Hogeveen and Brennan K. Berg

Received: 29 April 2014; in revised form: 15 November 2014 / Accepted: 24 November 2014 / Published: 28 November 2014

\begin{abstract}
To date, martial arts involvement is often described in controversial terms. While some studies report increased anti-social behavior as a result of martial arts involvement, other findings refer to a more positive social and personal development. This paradox has resulted in an ambiguous public discourse on their value and legitimacy as socially accepted sports, often leading to a dichotomization between "good" and "bad" styles of martial arts. Up until now however, there has been a lack of empirical proof that this "good versus bad" perspective divides along the lines of specific martial arts styles. Consequently, the distinct moral and medical concerns regarding the effects of involvement in harder martial arts_combined with their increased popularity, as well as their perceived positive outcomes for specific target groups-have resulted in a growing demand among policy makers to develop (or rethink) their strategy towards the regulation and support of these sports. By means of a case-study approach, the present paper discusses some of the key issues regarding the regulation of a number of full contact martial arts (e.g., kickboxing, Muay Thai, MMA), which are considered to be problematic for (sport) authorities, and which confront sports policy makers in Flanders. In describing the Flemish case, this paper aims to highlight the need to develop a sound martial arts policy that can provide a legitimation base for the provision and organization of full contact martial arts, which have become increasingly popular in recent years.
\end{abstract}


Keywords: full contact martial arts; governance; organization; policy

\section{Introduction}

Several studies have indicated that there is a high participation rate in martial arts (e.g., judo, karate, taekwondo, kickboxing) in a variety of countries (e.g., Australia [1]; Canada [2]; Europe [3]). A participation study including all countries in the European Union revealed that martial arts are often situated in the top 10 of most practiced sports in a club-related context (e.g., France, Spain, Italy, Slovenia, Poland) [3]. It is interesting to note that, throughout the years, the practice of harder variations (or types) of martial arts in particular (e.g., boxing, kickboxing, Thai boxing), referred to later in the paper as full contact martial arts ${ }^{1}$, has become increasingly popular [5,6]. And while in many countries most of these full contact martial arts are not recognized or supported by the government, nor are they on the list of Olympic disciplines, these sports receive a lot of attention internationally. Illustrative here is the organization of the World Combat Games, including not only more "traditional” martial arts (e.g., judo, karate, taekwondo, aikido, wrestling), but also harder martial disciplines, such as boxing, kickboxing, Muay Thai, savate. The first edition of this high-level international multi-sport event was organized in 2010 in Beijing and included 13 Olympic and non-Olympic martial arts. The second edition, which was held in Saint Petersburg (2013), featured 15 different sports. The World Combat Games are organized by SportAccord, the umbrella organization for international sports federations, which works in close collaboration with the International Olympic Committee (IOC). This clearly shows the increased international recognition of martial arts in general, and harder types in particular.

In light of this trend, it is worthwhile noting that some controversy exists with regard to the organization and practice of these martial arts. On the one hand, there is a belief that involvement in these types of martial arts can lead to positive socio-psychological outcomes (e.g., development of social capital, improved personal well-being) [7,8], and as such belief in their educational value. From this perspective, among other things, full contact martial arts are regarded as a developmental tool in working with youth at risk [9]. On the other hand, the practice of these types of martial arts raises distinct ethical and medical concerns for many. Most of the ethical concerns have been based on the assumed detrimental effects of full contact martial arts practice to the personal and social well-being of participants, in terms of aggressive and violent behavior [10]. This has often been linked specifically to youth involvement, which has resulted in an ambiguous public view as to their value as a youth activity. It has been indicated that these views are often largely based on perceptions created by the media and entertainment industry $[11,12]$. According to some, popular media have created a distorted image of martial arts for mere (commercial) entertainment purposes [13-15].

With regard to medical concerns, which have been raised concerning the practice of full contact martial arts, reference has often been made to the prevalence of injuries in these types of martial arts. Although it is often assumed that full contact martial arts participants are more susceptible to

1 Many different terms and definitions are used to refer to martial arts [4]. For the remainder of the present paper, we will use martial arts as a generic term, and use the term 'full contact martial arts' to refer to sports, such as boxing, kick-/Thaiboxing, Mixed Martial Arts (MMA), cage fighting, K1, full contact karate and sanda. 
injury [16,17], to date sound empirical proof is still lacking. For example, it remains unclear whether or not there is a higher occurrence of injuries in full contact martial arts compared to other sports. While some studies reported higher injury rates in full contact martial arts [17], other research did not $[18,19]$. Injury rates of full contact martial artists and other martial arts have also been compared. Findings have not always pointed in the same direction, however. While some studies reported a higher injury incidence among full contact martial arts compared to other martial arts (e.g., karate, taekwondo) [20], other research indicated that there were no differences [21].

Next to the ethical and medical concerns, full contact martial arts are confronted with some complex organizational issues. First, a wide variety of martial arts styles and disciplines exist, making it difficult to organize and regulate full contact martial arts. Several authors have attempted to develop a classification system, using a number of criteria (e.g., physical, functional, cultural, historical, philosophical). Some have made a distinction between martial arts and so-called "combat sports”, with the former being described as “...systems that blend the physical components of combat with strategy, philosophy, tradition, or other features, thereby distinguishing them from pure physical reaction” [22]. On the other hand, for the definition of combat sports reference could be made to "human target" [23]. This means that the objective of most combat sports is to show one's superiority over the rivals directly on the rivals' bodies (by employing different sets of techniques, such as throws, strangles, joint-locks, holds, punches, kicks, etc.) However, by far the most popular classification system divides martial arts according to cultural differences, such as "Eastern" versus "Western" [24]. In this context, as also indicated by Theeboom [4] a dichotomization often exists between the "good" and the "bad". The Eastern martial arts (e.g., karate, taekwondo, aikido), which are often more associated with positive and educational outcomes, are mostly considered as "good”. The Western martial arts (e.g., boxing, kickboxing), which are characterized by a strong emphasis on physical power and are more linked to aggression, violence and health-compromising behavior are regarded as "bad". For these reasons, the latter are often viewed from a negative perspective [10,25]. In this context it is interesting to refer to a number of authors who have described an evolution towards increasingly harder variants or types of martial arts. This trend, also described as "brutalization” [26] or "desportization” [27] of martial arts, not only entailed more medical concerns [28], it also led to a moral debate about the social acceptability of such types of martial arts [29-32]. In light of this, several authors have called for youngsters to be banned from participating in full contact martial arts, because of their assumed negative influences, based on medical, ethical, legal, and moral arguments [25,33,34]. However, as several authors have indicated, it is not clear that a ban would produce a better state of affairs. A ban may force the sport underground, where medical controls would be non-existent [35,36].

Furthermore, the wide variety of martial arts styles and disciplines is one of the reasons why many different associations and federations are involved in the organization of full contact martial arts. As a result, a fragmentation of the full contact martial arts structures exists [37,38]. For example many international boxing federations exist for boxing (e.g., World Boxing Council, WBC; World Boxing Association, WBA; World Boxing Organization, WBO; World Boxing Federation, WBF; International Boxing Federation, IBF; Women's International Boxing Federation, WIBF; Women's International Boxing Association, WIBA; International Boxing Union, IBU), while only one federation is recognized by SportAccord (i.e., International Boxing Association or Association Internationale de Boxe, AIBA). As a result, the federations without a controlling organization above them can escape 
certain regulations and are less controllable regarding, among other things, the ethical and medical concerns previously indicated. This situation occurs not only at an international level, but also at a national level (e.g., France [37], The Netherlands [38]). The fragmentation of the full contact martial arts sector creates a lack of clarity in their organization making it difficult for administrators and policy makers to support and regulate martial arts, especially full contact martial arts, in a clear-cut manner.

As a result, it is not surprising that policy makers struggle with the governance of full contact martial arts. According to Kikulis [39] "sports governance” is the responsibility for the functioning and overall direction of the organization, and is a necessary and institutionalized component of all sports codes from club level to national bodies, government agencies, sports service organizations and professional teams around the world. Despite the lack of clarity in a number of issues related to full contact martial arts, it is interesting to note that in several countries, policy makers endeavor to develop (or rethink) their strategy towards the regulation and support of full contact martial arts (The Netherlands [38], US [40,41], France [37]. However, governments sometimes do not know which stance to take regarding the legitimacy of full contact martial arts (e.g., in terms of recognition or banning), which often results in an ambiguous position. In the Netherlands, for example, on the one hand the government supports martial arts by subsidizing and licensing, yet on the other hand they have attempted to limit and even to ban full contact martial arts events [38].

Furthermore, in this context it is also interesting to consider the changing point of view of policy makers with regard to the legitimacy of, for example, Mixed Martial Arts (MMA) in the United States (US). Hess [42] indicated that MMA began in the nineties more as a spectacle than a legitimate sport, and the shocking nature of the practice led initially to statewide bans on MMA competition in the US. According to Varney [41], the introduction of more rules, weight classes, and eventual state regulation, also described as re-sportization [27], ensured that MMA became more popular and visible, and as a result many states lifted their ban on MMA. Although much has been accomplished in making the sport a mainstream success, there are still areas that need to be/could be improved upon (e.g., public image, the boundary between "real" and "mock" fighting, influence on spectators, point of view of politicians) $[27,41,43]$.

In conclusion, the full contact martial arts sector deals with some critical issues on a medical, ethical and organizational level. These concerns are often the main reason why governments do not know which stance to take regarding the legitimacy of full contact martial arts (e.g., in terms of recognition/subsidizing or banning).

\section{Purpose of the Study}

In order to obtain a better understanding of the ethical, medical and organizational concerns with which the full contact martial arts sector is confronted, scientific research into the governance of full contact martial arts is required. Although scientists from a wide range of disciplines (e.g., biomechanics, psychology, history, physiology, sociology, pedagogy, epidemiology of injuries) [44] have been paying increased attention to martial arts, until now only a limited number of studies have been conducted with regard to governance in martial arts [38,40,41].

By means of a case-study approach, the present paper will discuss some of the key issues regarding the regulation of a number of full contact martial arts which are considered to be problematic for 
(sports) authorities, and which confront sports policy makers in Flanders ${ }^{2}$. We decided to focus specifically on the situation in Flanders as the Flemish government has undertaken several steps in an attempt to tackle some of these concerns. In describing the Flemish case, this paper aims to highlight the need to develop a sound martial arts policy that can provide a legitimation base for the provision and organization of these full contact martial arts.

\section{Method}

In the period from October 2012 to February 2014 data were collected to obtain a better understanding of the specific situation with regard to the governance and organization of full contact martial arts in Flanders. More specifically, we attempted to list the problems, which confront the full contact martial arts sector, and to identify how policy makers have responded to this.

After conducting a literature review with regard to the organization and regulation of full contact martial arts, and analyzing sports participation data for these sports in Flanders, a document analysis regarding legislative and governance initiatives regarding full contact martial arts in Flanders as well as in other countries (particularly the Netherlands, US, England) was performed.

In addition, 58 interviews were conducted in order to obtain more insight into the experiences, problems, needs, expectations and opinions of different relevant stakeholders (in)directly involved in the regulation or organization of full contact martial arts in Flanders. More precisely, these stakeholders were representatives of all known full contact martial arts federations $(n=10)$, experts ${ }^{3}$ $(n=5)$ and referees $(n=2)$, representatives of the Flemish $(n=4)$ and local government $(n=13)$, physicians who have experience with full contact martial arts $(n=12)$, experts with regard to full contact martial arts in The Netherlands $(n=6)$, and representatives of other organizations indirectly involved in the organization of full contact martial arts (e.g., insurance companies, coordinating organizations responsible for medical examinations of sports participants, organization involved in the domain of ethics in sports) $(n=6)$. Full contact martial arts participants or athletes are not included in this research as a separate group because a sufficient number of the interviewees are (were) active as a participant.

In order to gain an overview of how full contact martial arts are regulated and organized in other countries beyond Flanders, an international survey was sent to (1) researchers involved in martial arts research and (2) national and international full contact martial arts federations which are linked to Flemish sports federations. In total, 12 researchers and 24 representatives of federations were asked to respond to the questionnaire. The response rate was however quite low, namely $31 \%$. This can be attributed to the fact that none of the full contact martial arts federations responded. In contrast to the federations, 11 out of the 12 researchers that we contacted filled in the questionnaire. These researchers were from different countries all over the world (i.e., Spain, Italy, Great-Britain, Poland, Japan, USA, Russia and The Netherlands).

2 Flanders is the Dutch-speaking northern part of Belgium.

3 Someone was considered as an expert when he or she had more than 20 years of experience with full contact martial arts as an athlete and more than 10 years of experience as a teacher. Moreover, most had experience with the practice of more than one full contact martial art. 
In addition, 4 focus group discussions were organized, three regarding medical aspects related to full contact martial arts in which several physicians with experience of this group of sports participated ( $n=4, n=4, n=19$ ). Another focus group was held regarding the guidance and education of those involved in the organization of full contact martial arts (i.e., teachers, referees, physicians) $(n=5)$. Present at the latter were representatives of different organizations: 2 full contact martial arts teachers, 1 member of the Flemish sport administration and 2 representatives of the department of the Flemish government that is responsible for the organization of courses for trainers.

Finally, 14 martial arts training sessions (3 for boxing and 11 for kick-/Thaiboxing), and 13 competitions of different full contact martial arts were attended, as well as 1 meeting of the executive board and 2 annual general assemblies of full contact martial arts federations.

Many different methods were used to gather the data of the present study. As indicated by Zohrabi [45], it is believed that using different types of procedures for collecting data and obtaining information through different sources augment the validity and reliability of the data and their interpretation. All interviews and focus groups were tape-recorded and most relevant aspects were transcribed verbatim. Afterwards the information was organized, processed and discussed with the different authors of the present study. The results of this study are often based on the discrepancies between (a) different interviewees and (b) what was told and what was seen during competitions and trainings.

\section{Results}

Before starting to describe the Flemish case, it is interesting to first take a look at the lessons that could be learned from other countries outside Flanders with regard to the regulation and organization of full contact martial arts.

\subsection{An International Survey Regarding the Organization and Regulation of Full Contact Martial Arts}

The international questionnaire revealed a number of general findings relating to organization, competition and coaches' education in full contact martial arts.

A first finding was that full contact martial arts are organized by recognized (by the government) or unrecognized (national) federations or organizations. Furthermore, it is reported that in most cases, full contact martial arts are organized within more than one sport federation, often with no collaboration. This results in a fragmented organizational setting per country and type of full contact martial art. Only in the United States does a particular structure exist today at governmental level, more specifically the State Athletic Commissions. Such a commission has a regulatory (umbrella) role with regard to full contact martial arts in particular states, regardless of the federations that are active in those states. As also indicated by Maher [40] and Berg and Chalip [46], the various state legislatures pass laws regulating full contact martial arts and commonly delegate authority to an administrative body, often a state athletic commission, to perform rule-making, licensing, operational, and enforcement functions.

Secondly, there appear to be a variety of providers of full contact martial arts competitions, such as federations and private organizations. If organized by the latter, a majority reported that little to no control exists with regard to the regulation of such events by local and national administrators. 
Thirdly, in all the participating countries a coaches education program for full contact martial arts teachers exists, which is mostly coordinated by a (governmental) coordinating organization responsible for the organization of trainer courses.

There may be several explanations for the fact that only limited information could be collected. First, as indicated in the introduction, researchers investigating the regulation and organization of full contact martial arts are scarce and, as a result, a limited number of researchers have knowledge regarding this topic in their country (The Netherlands [38]; US [40,41], France [37]). Secondly, most of those who do possess such knowledge are focused on only one full contact martial arts style and cannot provide a general view of how these sports are organized and regulated in their country. The latter limitation might also be applicable for the different full contact martial arts federations. Representatives of these federations can describe their particular situation, but they might not be able to give (objective) information on other federations. And thirdly, a language barrier exists, as most of the representatives of the federations do not speak English.

In conclusion, in most countries no coordinating federation or organization exists, which makes it difficult to obtain a general overview of the governance of full contact martial arts in other countries. Consequently, it seems even more relevant to obtain greater insight into how full contact martial arts are organized and regulated in one particular country.

\subsection{The Flemish Case}

Over a period of 17 months, we attempted to obtain a deeper insight into the organization and regulation of full contact martial arts in Flanders, using a number of means (i.e., document analysis, interviews with key witnesses, focus group discussions and observations of training sessions, competitions and events). In the following paragraphs we will first provide a list of the key issues that are considered to be problematic for (sports) authorities, and which confront the full contact martial arts sector as well as sports policy makers in Flanders. These key issues will be discussed from an organizational, pedagogical, ethical and medical, and governmental perspective. Secondly we will describe the different initiatives that Flemish policy makers have undertaken in response to the difficult issues related to full contact martial arts.

\subsubsection{Concerns Regarding Full Contact Martial Arts in Flanders}

\subsubsection{Organizational Perspective}

The full contact martial arts sector is confronted with some complex organizational issues, which make it difficult to regulate and organize full contact martial arts in a clear-cut way. Some examples:

- As a consequence of the wide variety of federations involved in the organization of full contact martial arts in Flanders, the full contact martial arts sector is fragmented. Despite the fact it is difficult to gain insight into which federations are involved with the organization of full contact martial arts, we made an attempt to provide a brief overview of the Flemish federations which have been identified until now (see Table 1):

o Four martial arts federations are recognized but not subsidized in Flanders. One of them offers only full contact martial arts (i.e., Flemish Boxing League). Two federations offer 
next to full contact martial arts, also other (styles of) martial arts (i.e., Flemish wushu federation and $\mathrm{ABC}$ Flanders). Finally, one of the four recognized federations is a multi-martial arts federation, which offers different martial arts, of which full contact martial arts are one.

o Three multi-sports federations offer, among other sports, full contact martial arts. Those sports federations are recognized and subsidized by the Flemish government. In Flanders, however, the regulations which multi-sports federations are required to meet in order to be recognized and subsidized are less comprehensive than those imposed on uni-sports federations, because they are not involved in multiple tasks, such as the organization of competition on a local, national and international level, talent development and elite sport development, etc. The focus of those multi-sports federations is particularly on the organization of recreational sports participation.

o Four martial arts federations, offering full contact martial arts are not directly recognized, but are affiliated with a recognized multi-sports or multi-martial arts federation.

o Finally also not recognized full contact martial arts federations exist in Flanders. Today, we could only identify one federation. Probably more full contact martial arts federations exist, but because they do not wish to be known, it is hard to obtain an overview of them.

- $\quad$ Some sports clubs do not have any affiliation with a sports federation. Even more so than full contact martial arts clubs that are a member of a sports federation, clubs without any affiliation are hard to control and regulate, because they are difficult to reach and less information is available about them. Particularly, in such clubs the ethically and medically sound sports participation is highly questionable.

- A profound distrust exists between the different full contact martial arts federations, which makes it difficult to set up any form of collaboration. This distrust has been historically grown. Often it is a slight disagreement (such as conflicts regarding competition results, financial disputes, etc.) which results in the impossibility of any kind of collaboration.

“... He is a renowned person in our martial arts style. But we, as a federation, could not continue to pay his personal expenses such as the wheels of his car. That is why he is split off from our federation." (A representative of a martial arts federation).

- Full contact martial arts participants and clubs can be a member of different federations. Because the federations do not have any information about each other, this leads to some critical issues. For instance, when a participant of a full contact martial art is suspended in one federation, he or she can participate at competitions organized by other federations. If the participant was suspended because of medical reasons (e.g., after a knock out) this can have consequences for the health of the participant. Moreover, each federation has its own competition rules and system to classify competitors according to their level of experience (e.g., elite-amateur, A-B-C-D). The phenomenon of "federation shopping" can raise several questions: How can the level of experience of a competitor be determined when each federation uses its own classification system? How can a competitor prepare him/herself thoroughly if he/she has to adapt him/herself to the rules that are applied? 
Table 1. Overview of Flemish federations offering full contact martial arts (boxing, kick-/Thaiboxing, Mixed Martial arts (MMA), cage fighting, K1, full contact karate and sanda). *

\begin{tabular}{|c|c|c|c|}
\hline $\begin{array}{l}\text { Recognized Martial Arts Federations } \\
\text { (Offering Full Contact Martial Arts) }\end{array}$ & $\begin{array}{l}\text { Flemish Multi-Sports Federations } \\
\text { (Recognized and Subsidized) (Offering } \\
\text { among Other Sports, Full Contact } \\
\text { Martial Arts) }\end{array}$ & & $\begin{array}{l}\text { Martial Arts Federations Not Directly } \\
\text { Recognized, but Affiliated with a } \\
\text { Recognized Multi-Sports or Multi- } \\
\text { Martial Arts Federation }\end{array}$ \\
\hline 1. ABC Flanders** (Kickboxing...) & $\begin{array}{l}\text { 1. Federation for Recreational and Omnisports } \\
\text { (FROS)** (Kick-/Thai boxing, MMA, } \\
\text { shoot boxing, K1, Full contact American } \\
\text { Kickboxing ...) }\end{array}$ & $\stackrel{* * *}{\leftarrow}$ & $\begin{array}{l}\text { 1. Flemish Kickboxing, Muaythai \& } \\
\text { MMA Organization (Kick-/Thai } \\
\text { boxing, MMA, shoot boxing, K1, } \\
\text { Full contact American } \\
\text { Kickboxing ...) }\end{array}$ \\
\hline 2. Flemish Boxing league (Boxing) & 2. SPORTA** (Muaythai, Boxing...) & & $\begin{array}{l}\text { 2. Belgian Karate Organisation } \\
\text { Shinkyokushin (full contact karate) }\end{array}$ \\
\hline 3. Flemish wushu federation** (Sanda) & $\begin{array}{l}\text { 3. Federation Dance and Sport** } \\
\text { (Kyokushinkai karate) } \\
\text { 4. }\end{array}$ & & $\begin{array}{l}\text { 3. Belgian Kyokushin Organisation (full } \\
\text { contact karate) } \\
\text { 4. Belgian Mixed Martial Arts } \\
\text { Federation (Kick-/Thai boxing, } \\
\text { MMA, full contact karate...) } \\
\text { 5. ... }\end{array}$ \\
\hline $\begin{array}{l}\text { 4. Flemish martial arts federation** } \\
\text { (Kick-/Thai boxing, MMA, full } \\
\text { contact karate ...) }\end{array}$ & $\leftarrow$ & & \\
\hline
\end{tabular}

* Only those federations known by the Flemish government are included in this table; ** Offers, next to full contact martial arts, also other (styles of) martial arts; *** Affiliated with ... 


\subsubsection{Pedagogical Perspective: Full Contact Martial Arts Coaches’ Education}

In Flanders, a department of the administration of the Flemish government leads the organization of a trainer course with regard to full contact martial arts. In order to guarantee the quality, the organization of trainer courses is based on a collaboration between the sports administration of the Flemish government, the recognized Flemish sports federations, three Flemish universities and 14 colleges offering an education in Physical education and Movement Sciences. The trainer course with regard to full contact martial arts focuses on historical, medical, ethical, didactical, safety, juridical, mental and deontological aspects of full contact martial arts, as well as on how to train youth practicing a full contact martial art. However, some concerns exist with regard to this course. Some examples:

- Because of the fragmentation as well as the wide variety of full contact martial arts, the trainer course is a general course for different full contact martial arts. This implies that no sports specific training course exists for boxing, kick-/Thaiboxing, MMA, etc.

- Only a limited number of full contact martial arts trainers have followed the trainer course organized by the department of the administration of the Flemish government. This is an issue concerning demand for-as well as supply of - the trainer course. With regard to the former, there is only limited interest and motivation to follow the training course, because the content of the existing course is not sufficiently well-known in the federations, or supported by specific federations. Regarding the supply chain, the training course is not accessible enough for full contact martial arts teachers, because many of them are low-skilled and/or immigrants. With regard to the latter also a language barrier exists.

- Very few full contact martial arts federations require recognized certification for a trainer to start a sports club. This carries the risk that participants of full contact martial arts are trained by insufficiently qualified trainers, meaning the safety of the participant cannot be ensured.

\subsubsection{Ethical and Medical Perspective}

In Flanders, a number of aspects suggest that the safety of participants is insufficiently guaranteed today. Some examples:

- In some full contact martial arts clubs and federations in Flanders, members are not obligated to have insurance. Some clubs and federations require this only of their competitors.

- Furthermore, a lack of clarity exists regarding compulsory protection (e.g., is it compulsory to wear a helmet?). Furthermore, differences exist in the protection material (e.g., leg protection: thick versus thin).

"The shin protection is sometimes treated in a stepmotherly way. Some have really very thin, other very thick protection. There is a big difference between the impact of a blow to the head with such a light protection, that has mostly moved to the wrong side during the fight, as compared with a thick shin protection.” (A physician)

- No clear agreement exists with regard to the medical examination of a participant of a full contact martial art (e.g., before a competition, after a medical suspension period, etc.) 
- Because of the fragmentation of the full contact martial arts sector and the problem of "federation shopping", discussed previously, no general system exists, with regard to checking the medical status of participants. Each federation has its own system, and as a result there is no general registration of the total number of competitions with an indication of wins/losses, injuries sustained, knock-outs, ...

- A lack of clarity exists with regard to the authority of a physician during competition.

- In most federations, the specific regulations with regard to youth are vague. For example, in some federations punching to the head is allowed, but participants are not allowed to hit "hard".

"It is written in the rules that youth cannot make hard contact, but in fact this is bullshit, because what is 'hard'? 'Hard' for the one is different for another." (Expert in full contact martial arts)

Some additional ethical issues related to full contact martial arts are interesting to note:

- The commercialization of full contact martial arts events can be considered as an ethical issue. The commercial gain of such events is often considered more important than the safety of the participants.

- In Flanders, popular media have created a distorted image of full contact martial arts, by focusing on a one-sided, negative account, primarily with regard to the negative medical impact of practicing full contact martial arts [47-49].

\subsubsection{Governmental Perspective}

Finally, also from a governmental perspective some issues which confront the full contact martial arts sector, as well as sports policy makers, in Flanders could be raised. Some examples:

- There is lack of clarity in the vision of the Flemish government. For more than a decade, one of the pillars of the Flemish sports subsidization policy relies on the existence of a selected list of 54 sports that are eligible for official recognition and financial support by the Flemish government. The list includes 10 different martial arts (aikido, amateur boxing, fencing, jiu-jitsu, judo, karate, kendo, taekwondo, wrestling and wushu). Apart from amateur boxing (because of its Olympic status), no other full contact martial arts are included. This is mainly because of distinct medical and moral concerns that were raised. The lack of clarity in the vision of the Flemish government relates to the fact that on the one hand limited recognition and no support is allowed for participants of full combat martial arts, such as Thai and kickboxing (because they are not on the official sports list), while on the other hand, the same government supports a number of sports-based developmental initiatives that make use of these sports.

- The Flemish government uses a specific term to refer to full contact martial arts, namely "risk" martial arts. This term refers to those martial arts that have specific techniques which permit punching or kicking an opponent with the intention of reducing his/her physical or psychological integrity (Decree of 13 July 2007 on medically and ethically sound sports participation, Art. 2, §13). Based on the interviews with expert witnesses as well as on what was heard during attendance of different competitions, trainings and meetings, we can indicate that the introduction and the use of this term has caused consternation among different 
individuals involved with martial arts practice. According to many of those involved in full contact martial arts the use of this term promotes negative stereotyping, and is not positive for the image of this kind of martial arts.

In order to improve the image of our martial arts, we have to take our own responsibility and emphasize the positive aspects.... This is however very difficult when you are called “risk martial arts”. (A representative of a martial arts federation).

Besides the Flemish government, the local authorities are also confronted with some difficulties regarding the regulation of full contact martial arts.

- Municipalities and cities are unaware of the problems and the possible abuses that occur in full contact martial arts (e.g., rental of locations to organizations which are not practicing/organizing martial arts in a medically sound way).

- Municipalities and cities can determine the criteria that sports clubs have to fulfill in order to obtain financial support. Often a sports club is not required to be a member of a recognized sports federation. Because of this, it is possible for a local sports club to receive the financial support of the local authorities without being a member of a sports federation. As they receive the financial support of the local authorities, they do not feel the need to be affiliated with a sports federation. As indicated earlier, such clubs are less controllable and often, even more than those that are a member of a sports federation, the ethically and medically sound sports participation is highly questionable in these clubs.

\subsubsection{Initiatives of the Flemish Government Regarding Full Contact Martial Arts}

Despite the complex and numerous difficulties with regard to full contact martial arts in Flanders, the practice of these sports has become increasingly popular. Flemish participation data show that the number of participants practicing full contact martial arts (e.g., kick-/Thaiboxing, boxing and MMA) has increased from 783 in 2002 to 5718 participants in 2011. Since 2007, the Flemish government has undertaken different steps with regard to the governance of full contact martial arts. These different steps will be described more in detail below.

In 2007, the Flemish government passed a decree regarding medically and ethically sound sports participation in which the term "risk" martial arts was introduced. Two years later, as a consequence of this decree, Flanders set up an expert committee including policy officers, martial arts representatives and physicians. Its task is to advise the Minister of Sports regarding the conditions for a medically sound practice and delivery of full contact martial arts instruction in Flanders. Among other things, the committee has proposed a set of generic guidelines with a dual purpose. On the one hand it should give the Flemish government standards that allow her to test the obligations that sports federations have, in order to guarantee medically and ethically sound sports participation. On the other hand, those guidelines have to give more clarity to sports federations who organize full contact martial arts on how they can comply with the decree regarding medically and ethically sound sports participation. To date however, there is no formal obligation that requires sports federations to act according to these guidelines. If it were a formal obligation, the Flemish government would control the fulfillment of these guidelines, with financial implications. 
Additionally, in 2011 a round table conference was organized on behalf of the Minister of Sports. In total 94 participants attended the conference. The aim of this conference was to create more public support for the generic guidelines, and to offer the possibility to representatives of different sectors (i.e., government, martial arts, health, welfare, education, youth, etc.) to exchange relevant information regarding the practice and the organization of martial arts. Furthermore, by listing the experiences, problems, needs, expectations and opinions of relevant stakeholders it was aimed to obtain a better understanding of the specific issues with which the martial arts sector is confronted.

Finally, based on the results of this conference, at the beginning of 2013 the Flemish government decided to set up a Flemish Platform on full contact martial arts. This platform was formed in the context of an experimental project in which two fulltime employees were appointed for a duration of two years. In general, the platform aims to provide more professional and qualitative support to those involved in the organization of full contact martial arts in Flanders, and to encourage collaboration between the various actors involved. More specifically, this is reflected in three major assignments:

- The platform is a knowledge center to extend knowledge with regard to the different aspects of full contact martial arts;

- The platform is a communication center and contact point: a center which will inform and communicate regarding full contact martial arts with all sorts of stakeholders (e.g., federations, government, etc.) on a regular basis;

- The platform is a service and support center for stakeholders involved in the organization or the practice of full contact martial arts.

Finally, it should be noted that the Flemish government should pay attention that, besides the fragmentation of the full contact martial arts sector itself, no fragmentation occurs at policy level, as the role of the different initiatives (e.g., expert committee, Flemish Platform on full contact martial arts) is not always very clear.

\section{Conclusions}

Despite the increasing popularity of full contact martial arts, today the full contact martial arts sector is confronted with some ethical, medical and organizational concerns which make it difficult for administrators and policy makers to support and regulate these sports in a clear-cut manner. The aim of the present paper was to highlight the need to develop a sound full contact martial arts policy. This was achieved by describing the Flemish situation, more specifically by describing (1) the key issues considered to be problematic for the full contact martial arts sector as well as sports policy makers in Flanders and (2) how the Flemish government has responded to these problems since 2007. It can be concluded that a number of concerns exist in Flanders with regard to the organization and regulation of full contact martial arts. However, a positive evolution is noticeable, as the Flemish government has undertaken different steps in order to outline a policy with regard to the regulation of full contact martial arts. One of the policy tools used by the Flemish government in their attempt to regulate the full contact martial arts sector was the formation of the Flemish Platform on full contact martial arts. However, it should be noted that several difficulties still need to be overcome in Flanders, at the level of the government (e.g., how to pursue a full contact martial arts policy and obligate sports federations 
to act according to this policy?), of the martial arts sector (e.g., how to increase the limited number of well-educated full contact martial arts teachers?), as well as at the level of the martial arts clubs (e.g., how to deal with safety matters in the sports club?). Furthermore, it will be necessary to refine the data used in the present study because the underlying reasons behind certain aspects need further clarification. For example, (a) the influence of international federations at the national level and (b) which responsibilities should be taken by the government and which by the martial arts sector?

The Flemish case is not a single one, however. In other words, the difficulties with regard to governance in full contact martial arts are not bound to geographical places or limited to specific countries [50]. It will not be enough to tackle these difficulties at the local and national level, because it leaves the possibility for full contact martial arts organizations to escape from more regulated countries to less strict regulated countries. Therefore the governance of full contact martial arts should be regarded as a transnational issue. Consequently, the question can be raised as to which role the European Union (EU) can fulfill. In this context, it is interesting to note that one of the programs of the European Commission aims to tackle cross-border threats to the integrity of sport and to promote and support good governance in sport [51]. Within this scope, it might be relevant to think in terms of the development of an international coherent policy with regard to full contact martial arts. However, it will be difficult to achieve the right balance between the rules enforced by the EU and the freedom of local and national self-regulation.

Furthermore, the deterritorialization and globalization of full contact martial arts requires research at a supranational level. This kind of research could be helpful to gain more of an insight into solving the problems related to governance, regulation and management of martial arts, especially within an international context. The increased need to exchange knowledge and experience concerning the regulation and support of full contact martial arts can be illustrated by the organization of a workshop on the organization and regulation of martial arts during the 21st annual conference of the European Association of Sport Management (EASM) in 2013. At the end of this workshop, it was concluded that more initiatives are needed to initiate and stimulate research cooperation, to exchange relevant information and to consider the option of developing an international network of researchers and policy makers involved in organizing, managing and regulating martial arts [50]. Consequently, more research is necessary with regard to the regulation of full contact martial arts from an organizational and governance policy perspective. In this kind of research, several issues could be raised, such as should full contact martial arts be banned by law or not? If so, what would be the consequences? If not, which rules and conditions are necessary in order to guarantee medically and ethically sound sport participation. In addition, it would be relevant to examine whether the regulation and the organization of full contact martial arts is the responsibility of the government or the martial arts sector itself. Alternatively, as suggested by Berg and Chalip [46] and Koppenjan and Klijn [52], it might be preferable for the full contact martial arts sector to work together with governments to tackle the difficulties with regard to these sports. In this case it would be necessary to examine how the government and the sector relate to each other.

Finally, we would like to focus on the increasing interest in the use of full contact martial arts as a developmental tool [53]. Despite the fact this is a positive evolution with regard to full contact martial arts, this should be viewed from a critical point of view. The simple fact that people engage in a sport setting does not automatically imply that improvements in personal or social outcomes can be expected. 
It therefore becomes clear that more attention must be paid to the structural components and processes of management and guidance within the sports context in general, in our case within full contact martial arts, in order to provide greater insight into the complexity of the underlying processes that are presumed to generate social benefits [54-56]. A more modest perspective and more research that tries to obtain insight into the underlying conditions and processes producing developmental outcomes would contribute to a deeper understanding of any effects.

In conclusion, the complex issues that confront full contact martial arts, need a local and international approach as well as further investigation. By stimulating research cooperation and exchanging knowledge and experience, more insight could be obtained into the governance, provision and organization of full contact martial arts, which in turn can provide a legitimation base for the development of a sound martial arts policy. Better organization and regulation of the full contact martial arts sector might be helpful in developing towards a more accepted, respected and recognized group of sports.

\section{Author Contributions}

Jikkemien Vertonghen, Els Dom and Marc Theeboom developed the methodology. Els Dom, and to a lesser extent Jikkemien Vertonghen, collected the data and together with Marc Theeboom they analyzed these data. Jikkemien Vertonghen, and to a lesser extent Els Dom and Marc Theeboom, wrote the paper. Veerle De Bosscher and Reinhard Haudenhuyse provided meaningful feedback.

\section{Conflicts of Interest}

The authors declare no conflict of interest.

\section{References}

1. Australian Bureau of Statistics. Children's Participation in Cultural and Leisure Activities, Australia, Apr 2009. Available online: http://www.abs.gov.au/AUSSTATS/abs@.nsf/DetailsPage/ 4901.0Apr\%202009?OpenDocument (accessed on 21 January 2010).

2. Ifedi, F. Sport Participation in Canada 2005; Culture, Tourism and the Centre for Education Statistics: Ottawa, ON, Canada, 2008.

3. Van Bottenburg, M.; Rijnen, B.; van Sterkenburg, J. Sports Participation in the European Union. Trends and Differences; Mulier Institute: Amsterdam, The Netherlands, 2005.

4. Theeboom, M. A closer look at effects of martial arts involvement among youth. Int. J. Sport Manag. Mark. 2012, 11, 193-205.

5. Brent, J.; Kraska, P. Fighting is the most real and honest thing: Violence and the Civilization/Barbarism Dialectic. Br. J. Criminol. 2013, 53, 357-377.

6. Theeboom, M.; Vertonghen, J.; Dom, E. The regulation of "risk" martial arts: The case of Flanders. In Book of Abstracts, Proceeding of the 21th Conference of the European Association for Sport Management (EASM), Istanbul, Turkey, 11-15 September 2013; pp. 79-80.

7. Fulton, J. “What's your worth?”-The development of capital in British boxing. Eur. J. Sport Soc. 2011, 8, 192-218. 
8. Haudenhuyse, R.; Theeboom, M.; Coalter, F. The potential of sports-based social interventions for vulnerable youth: Implications for sport coaches and youth workers. J. Youth Stud. 2012, 15, 437-454.

9. Theeboom, M.; Wylleman, P.; de Knop, P. Martial arts and socially vulnerable youth: An analysis of Flemish initiatives. Sport Educ. Soc. 2008, 13, 301-318.

10. Endresen, I.M.; Olweus, D. Participation in power sports and antisocial involvement in preadolescent and adolescent boys. J. Child Psychol. Psychiatry 2005, 46, 468-478.

11. Grady, J. Celluloid katas: Martial arts in the movies-A practitioner's prejudices. J. Asian Martial Arts 1998, 7, 86-101.

12. Smith, R. Martial Musings: A Portrayal of Martial Arts in the 20th Century; Via Media Publishing: Erie, PA, USA, 1999.

13. Fu, P.; Desser, D. The Cinema of Hong Kong: History, Arts, Identity; Cambridge University Press: Cambridge, UK, 2000.

14. Taylor, K. Martial Media. In Martial Arts of the World: An Encyclopedia of History and Innovation; Green, T.A., Svinth, J.R., Eds.; ABC-CLIO: Santa Barbara, CA, USA, 2010; pp. 527-554.

15. Hunt, L. Kung Fu Cult Masters: From Bruce Lee to Crouching Tiger; Wallflower Press: London, UK, 2003.

16. Ngai, K.M.; Levy, F.; Hsu, E.B. Injury trends in sanctioned mixed martial arts competition: A 5-year review from 2002 to 2007. Br. J. Sports Med. 2008, 42, 686-689.

17. Junge, A.; Engebretsen, L.; Mountjoy, M.L.; Alonso, J.M.; Renström, P.; Aubry, M.J.; Dvorak, J. Sports Injuries During the Summer Olympic Games 2008. Am. J. Sports Med. 2009, 37, 2165-2172.

18. Pappas, E. Boxing, Wrestling, and Martial Arts Related Injuries Treated in Emergency Departments in the United States, 2002-2005. J. Sports Sci. Med. 2007, 6, 58-61.

19. Porter, M.; O’Brien, M. Incidence and severity of injuries resulting from amateur boxing in Ireland. Clin. J. Sport Med. 1996, 6, 97-101.

20. Gartland, S.; Malik, M.H.A.; Lovel, M.E. A Prospective Study of Injuries Sustained during Competitive Muay Thai Kickboxing. Clin. J. Sport Med. 2005, 15, 34-36.

21. Gartland, S.; Malik, M.H.A.; Lovel, M.E. Injury and injury rates in Muay Thai kick boxing. Br. J. Sports Med. 2001, 35, 308-313.

22. Green, T.A.; Svinth J.R. Introduction. In Martial Arts of the World: An Encyclopedia of History and Innovation; Green, T.A., Svinth, J.R., Eds.; ABC-CLIO: Santa Barbara, CA, USA, 2010; p. xix.

23. Parlebas, P. Jeux, Sports et Sociétés, Lexique de Praxéologie Motrice [Game, Sports and Society, Lexicon of Motor Praxeology]; Institut National du Sport, de L'expertise et de la Performance (INSEP): Paris, France, 1999.

24. Donohue, J.; Taylor, K. The classification of the fighting arts. J. Asian Martial Arts 1994, 3, 10-37.

25. Pearn, J. Boxing, youth and children. J. Paediatr. Child Health 1998, 34, 311-313.

26. Förster, A. The nature of martial arts and their change in the West. In Mind and Body: East Meets West; Kleinman, S., Ed.; Human Kinetics: Champaign, IL, USA, 1986; pp. 83-88.

27. Van Bottenburg, M.; Heilbron, J. De-sportization of fighting contests: The origins and dynamics of no holds barred events and the theory of sportization. Int. Rev. Sociol. Sport 2006, 41, 259-282.

28. Buse, G.J. No holds barred sport fighting: A 10 year review of mixed martial arts competition. Br. J. Sport Med. 2006, 40, 169-172. 
29. Sheard, K.G. Aspects of boxing in the Western "Civilizing Process”. Int. Rev. Sociol. Sport 1997, 32, 31-57.

30. Carr, D. What moral significance has physical education? A question in need of disambiguation. In Ethics and Sport; McNamee, M.J., Ed.; E. \& F.N. Spon: London, UK, 1998; pp. 119-133.

31. Parry, J. Violence and aggression in contemporary sport. In Ethics and Sport; McNamee, M.J., Ed.; E. \& F.N. Spon: London, UK, 1998; pp. 205-224.

32. Steenbergen, J. Grenzen aan de Sport: Een Theoretische Analyse van het Sportbegrip [Frontiers to Sport: A Theoretical Analysis of the Sport Concept]; Elsevier: Maarssen, The Netherlands, 2004.

33. American Academy of Pediatrics. Boxing participation by Children and Adolescents. Pediatrics 2011, 128, 617-623.

34. World Medical Association. WMA Statement on Boxing. Available online: http://www.wma.net/ en/30publications/10policies/b6/index.html (accessed on 1 September 2010).

35. Gauthier, J. Ethical and Social Issues in Combat Sports: Should Combat Sports be Banned? In Combat Sports Medicine; Kordi, R., Maffulli, N., Wroble, R., Wallace, A., Eds.; Springer: London, UK, 2009; pp.151-172.

36. Jones, K. A key moral issue: Should boxing be banned? Sport Soc. 2001, 4, 63-72.

37. Collinet, C.; Delalandre, M.; Schut, P.; Lessard, C. Physical Practices and Sportification: Between Institutionalisation and Standardisation. The Example of Three Activities in France. Int. J. Hist. Sport 2013, 30, 989-1007.

38. Dortants, M.; van Bottenburg, M. Aanzien en overleven in een sport vol passie [Respect and Survive in a Sport Full of Passion]. In Over Regulering van Full Contact-Vechtsporten [Regulation of Full Contact Martial Arts]; Arko Sports Media: Nieuwegein, The Netherlands, 2013.

39. Kikulis, L. Continuity and change in governance and decision making in national sport organizations: Institutional explanations. J. Sport Manag. 2000, 14, 293-320.

40. Maher, B. Understanding and Regulating the Sport of Mixed Martial Arts; University School of Law: Oklahoma City, OK, USA, 2010.

41. Varney, G. Fighting for respect: MMA's struggle for acceptance and how the Muhammad Ali act would give it a sporting chance. West Va. Law Rev. 2010, 112, 269-305.

42. Hess, P. The development of mixed martial arts: From Fighting Spectacles to State-Sanctioned Sporting Events. Willamette Sports Law J. 2007, 4, 1-23.

43. Sanchez Garcia, R.; Malcolm, D. Decivilizing, civilizing or informalizing? The international development of Mixed Martial Arts. Int. Rev. Sociol. Sport 2010, 45, 39-58.

44. Distaso, M.; Maietta, A.; Giangrande, M.; Villani, R. The state of the art of scientific research in combat sports. In Book of Abstracts, Proceedings of the 14th annual Congress of the European College of Sport Science, Oslo, Norway, 24-27 June 2009; p. 599.

45. Zohrabi, M. Mixed Method Research: Instruments, Validity, Reliability and Reporting Findings. Theory Pract. Lang. Stud. 2013, 3, 254-262.

46. Berg, B.K.; Chalip, L. Regulating the emerging: A policy discourse analysis of mixed martial arts legislation. Int. J. Sport Policy Polit. 2013, 5, 21-38.

47. De Smedt, L. Wij Krijgen Onterecht Stempel Crimineel [We Obtain Unfairly the Stamp of a Criminal]. Available online: http://www.nieuwsblad.be/article/detail.aspx?articleid=DMF 20131009_00782826 (accessed on 11 October 2013). 
48. Op de Beek, H. 20 Redenen Waarom deze Gevechtsport zo Gevaarlijk is [20 reasons why martial arts are dangerous]. Available online: www.hln.be/hln/nl/956/Meer-Sport/article/detail/1777518/2014/ 01/20/20-redenen-waarom-deze-gevechtssport-zo-gevaarlijk-is.dhtml (accessed on 3 February 2014).

49. Vermeiren, M. Sugar Jackson werd Jarenlang Slecht Begeleid [Sugar Jackson was poorly guided for many years]. Available online: http://www.vandaag.be/sport/137822_sugar-jackson-werdjarenlang-slecht-begeleid.html (accessed on 3 February 2014).

50. Vertonghen, J.; Dortants, M. Report on the workshop "Organising, Managing and Regulating Martial Arts” during the 21st EASM Conference. Rev. Artes Marciales Asiáticas 2014, 8, 480-483.

51. European Commission. Erasmus + Programme Guide, 2014. Available online: http://ec.europa.eu/ programmes/erasmus-plus/documents/erasmus-plus-programme-guide_nl.pdf (accessed on 19 February 2014).

52. Koppenjan, J.; Klijn, E. Managing Uncertainties in Networks. A Network Approach to Problem Solving and Decision Making; Routledge: London, UK, 2004.

53. Theeboom, M.; Verheyden, E. Vechtsporten met een Plus: Extra Kansen voor Kwetsbare Jongeren [Martial Arts with a Plus: Additional Opportunities for Socially Deprived Youth]; Vubpress: Brussel, Belgium, 2011.

54. Chalip, L. Toward a Distinctive Sport Management Discipline. J. Sport Manag. 2006, 20, 1-21.

55. Theeboom, M.; Schaillée, H.; Nols, Z. Social capital development among ethnic minorities in mixed and separate sport clubs. Int. J. Sport Policy Polit. 2011, 4, 1-21.

56. Vertonghen, J.; Theeboom, M. How to Obtain More Insight into The True Nature of Outcomes of Youth Martial arts practice? J. Child. Serv. 2013, 8, 244-253.

(C) 2014 by the authors; licensee MDPI, Basel, Switzerland. This article is an open access article distributed under the terms and conditions of the Creative Commons Attribution license (http://creativecommons.org/licenses/by/4.0/). 